\title{
Polifenóis totais e avaliação sensorial de suco de uvas Isabel tratadas com ultrassom
}

\author{
Phenolic compounds and sensory evaluation of \\ juice from Isabel grapes treated with ultrasound
}

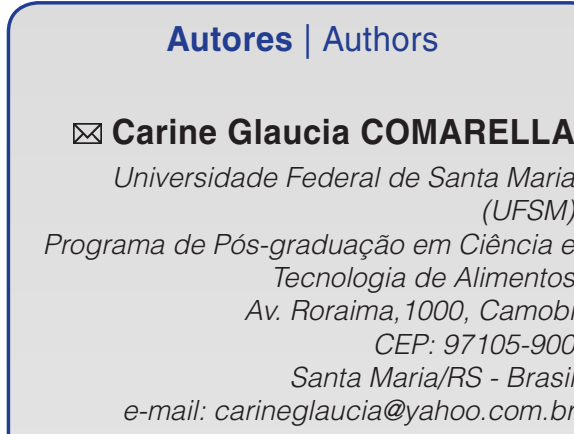

Claudia Kaehler SAUTTER

Universidade Federal de Santa Maria (UFSM)

Departamento de Tecnologia e Ciência dos Alimentos

Santa Maria/RS - Brasil e-mail:cksautter@gmail.com

Leandro Correia EBERT

Universidade Federal de Santa Maria (UFSM)

Curso de Agronomia

Santa Maria/RS - Brasil

e-mail: leandroebert@yahoo.com.br

Neidi Garcia PENNA

Universidade Federal de Santa Maria (UFSM)

Departamento de Tecnologia e Ciência dos Alimentos

Santa Maria/RS - Brasil e-mail:ngpenna@gmail.com

$\square$ Autor Correspondente / Corresponding Author Publicado / Published: dezembro/2012

\section{Resumo}

O suco de uva no Brasil é um produto amplamente consumido por suas características sensoriais e nutricionais; porém, tratamentos durante o seu processamento podem ocasionar perdas de compostos fenólicos importantes na definição dessas características. O ultrassom é apontado como um possível elicitor desses compostos, visto que o estresse mecânico provocado por cavitação acústica e microagitação estimula respostas de defesa na planta que levam à síntese dessas substâncias. Neste estudo, diferentes densidades de potência (53 e 113 W. $\mathrm{cm}^{-2}$ ) e tempos de exposição (1, 5 e 10 minutos) de ultrassom foram aplicados em uvas Isabel e seu efeito sobre o conteúdo de polifenóis totais e o aspecto sensorial dos sucos foi avaliado. O ultrassom causou um acréscimo de até $83 \%$ no teor de polifenóis totais, melhorando também as características sensoriais dos sucos, tendo sido estes os preferidos pelos provadores.

Palavras-chave: Ultrassom; Elicitor; Fitoalexinas; Polifenóis; Suco; Uva.

\section{Summary}

Grape juice in Brazil is a product widely consumed for their sensory and nutritional characteristics, however, treatments during processing can cause loss of phenolic compounds important in defining these characteristics. Ultrasound is cited as a possible elicitor of these compounds, since the mechanical stress caused by acoustic cavitation and microstreaming stimulates the plant defense responses that lead to synthesis of these substances. In this study, different power densities (53 and $113 \mathrm{~W} . \mathrm{cm}^{-2}$ ) and exposure times (1,5 and 10 minutes) of ultrasound were applied in Isabel grapes and its effect on the total polyphenols content and sensory aspect of the juices was evaluated. The ultrasound caused an increase of up to $83 \%$ in total polyphenols content, improving the sensory characteristics of juices, being chosen as preferred by the tasters.

Key words: Ultrasound; Elicitor; Phytoalexins; Polyphenols; Juice; Grape. 


\section{Introdução}

A crescente busca por alimentos que não somente supram as necessidades básicas energéticas, mas que também desempenhem outras funções benéficas ao organismo, impulsiona as pesquisas visando o desenvolvimento de novas tecnologias capazes de agregar valor nutricional ao alimento, sem acarretar perdas na qualidade sensorial, ao mesmo tempo em que proporcionam um produto seguro ao consumidor e com a mínima geração de resíduos danosos ao meio ambiente.

Os processos físicos vêm ganhando notória importância, como tecnologia eficiente para substituir tratamentos químicos convencionais. Neste âmbito, - ultrassom (US) representa uma nova forma de exploração de energia limpa, que pode ser usada nas indústrias de diferentes segmentos, dentre os quais, o alimentício. Esta tecnologia vem sendo empregada na melhoria do processamento direto de alimentos, tais como limpeza de superfícies; aumento da desidratação; secagem e filtração; inativação de microrganismos e enzimas; extração de enzimas, proteínas e compostos antioxidantes; ruptura de células; desgaseificação de alimentos líquidos, e aceleração de transferência de calor (KNORR et al., 2004). Mais recentemente, especial atenção tem sido dada à potencial aplicação do US em estimular a biossíntese de metabólitos secundários em tecidos vegetais (SALES e RESURRECCION, 2010; REZAEl et al., 2011). A síntese desses metabólitos está geralmente associada a respostas de defesa da planta contra a invasão de patógenos (ZHAO et al., 2005). Os agentes e meios que podem ativar os mecanismos de defesa são usualmente referidos como elicitores. Não somente de origem biótica, como os agentes microbianos, os elicitores podem envolver vários estímulos físicos e mecânicos, sendo então denominados elicitores abióticos. Dessa maneira, o US atua como elicitor abiótico, gerando estresse mecânico e microagitação induzidos por cavitação acústica e seus eventos hidrodinâmicos secundários, como a formação de espécies reativas de oxigênio (LIN et al., 2001).

Em trabalhos realizados por Nascimento et al. (2008) e Sales e Resurreccion (2010), o uso do US em café despolpado e amendoins, respectivamente, causou o aumento do conteúdo de compostos fenólicos desses produtos. Estes compostos são amplamente distribuídos na natureza e recebem atualmente grande atenção em virtude de seus efeitos benéficos à saúde, promovidos principalmente por sua capacidade antioxidante (NETZEL et al., 2007). A uva é uma das maiores fontes de compostos fenólicos, os quais também podem ser encontrados em produtos como o suco. Embora importante fonte de fenólicos, a quantidade e o tipo destes compostos no suco não são necessariamente os mesmos da fruta fresca. Determinados tratamentos aos quais a uva e o mosto são submetidos durante a produção do suco podem interferir na quantidade desses compostos presentes na bebida. Nos últimos sete anos, o mercado de suco no Brasil apresentou um crescimento de até 300\% (IBRAVIN, 2011), de modo que a busca por alternativas que minimizem as perdas durante o processamento agregando qualidade à bebida pode refletir sobremaneira em benefícios à saúde do consumidor, além de reforçar o apelo comercial deste produto.

Dessa forma, este trabalho visou avaliar o efeito de diferentes densidades de potência de ultrassom (53 e 113 W. $\mathrm{cm}^{-2}$ ) e tempos de exposição (1, 5 e 10 minutos) em uvas Isabel sobre o conteúdo de polifenóis totais do suco, bem como a influência sobre o aspecto sensorial do produto.

\section{Material e métodos}

As uvas Isabel utilizadas no experimento foram colhidas na cidade de Caxias do Sul-RS no ano de 2011 e mantidas em câmara de refrigeração a $20{ }^{\circ} \mathrm{C}$ por um período de dois dias, anterior aos tratamentos, para retirada do calor de campo e estabilização do metabolismo da fruta.

Para a sonicação, foram utilizados processadores ultrassônicos (Sonics and Materials, Inc., Newton, USA) com potência nominal de 130 W (modelo VCX 130 PB) e 750 W (modelo VC 750), com amplitude de onda de $70 \%$ e frequência constante de $20 \mathrm{kHz}$. O experimento foi conduzido em triplicata utilizando-se diferentes densidades de potência de US (53 W. $\mathrm{cm}^{-2}$ e $\left.113 \mathrm{~W} . \mathrm{cm}^{-2}\right)$ e tempos de exposição (1, 5 e 10 minutos), em delineamento inteiramente casualizado, resultando em seis tratamentos identificados como: T1 (53 W.cm-2 por 1 minuto); T2 (53 W. $\mathrm{cm}^{-2}$ por 5 minutos); T3 (53 W. $\mathrm{cm}^{-2}$ por 10 minutos); T4 (113 W.cm ${ }^{-2}$ por 1 minuto); T5 (113 W. $\mathrm{cm}^{-2}$ por 5 minutos), e T6 (113 W. $\mathrm{cm}^{-2}$ por 10 minutos). Amostras controle foram preparadas com uvas não irradiadas. Cerca de $1 \mathrm{~kg}$ de cachos de uvas Isabel foi mergulhado em recipiente contendo água destilada e a sonda foi então introduzida no centro do mesmo a uma profundidade de $1,5 \mathrm{~cm}$, mantendo-se constante a temperatura do meio em $20^{\circ} \mathrm{C}$. Sob a mesma temperatura, as amostras sonicadas e controle permaneceram em período de incubação por cinco dias em câmara de refrigeração, seguindo então, para o congelamento $\mathrm{a}-20^{\circ} \mathrm{C}$ até o processamento das amostras.

Para a preparação dos sucos, seguiu-se o método de maceração sulfurosa a frio das bagas, denominado Flanzy. As uvas foram lavadas e esmagadas, acondicionadas em garrafas de vidro de $500 \mathrm{~mL}$ e, então, aquecidas em banho-maria a $85^{\circ} \mathrm{C}$ por 15 minutos. Depois de resfriadas naturalmente, procedeu-se à sulfitagem (260 ppm de metabissulfito de potássio) e posterior remontagem por três dias a $25^{\circ} \mathrm{C}$. Após a prensagem do mosto, o suco obtido foi novamente armazenado em garrafas, aquecido a $50^{\circ} \mathrm{C}$ e então filtrado em bomba de vácuo. A estabilização do bitartarato de potássio foi feita resfriando-se o suco a $5{ }^{\circ} \mathrm{C}$ por uma semana. No final 
deste período, os sucos foram trasfegados para outro recipiente e mantidos em refrigeração até a realização da análise sensorial, enquanto que alíquotas destinadas às análises químicas seguiram para o congelamento.

A determinação da concentração de polifenóis totais (PT) no suco de uva foi realizada por meio da reação com reagente de Folin Ciocalteau e da leitura da absorbância em comprimento de onda de $765 \mathrm{~nm}$, conforme o método descrito por Singleton e Rossi (1965). A análise foi realizada em triplicata para todas as amostras e soluções padrões. Os resultados foram expressos em equivalentes de ácido gálico (mg.L-1 EAG).

Amostras de suco de uvas controle e sonicadas (T3, T5 e T6), selecionadas segundo os resultados mais significativos de PT e/ou estatisticamente diferentes entre si, foram submetidas a um teste de ordenação de preferência sensorial, segundo as normas do Instituto Adolfo Lutz (IAL, 2008), por um painel não treinado constituído de 43 provadores. A pesquisa e seus procedimentos foram aprovados pelo Comitê de Ética em Pesquisa da Universidade Federal de Santa Maria.

Os dados foram submetidos à análise de variância (ANOVA) e a comparação de médias deu-se por meio do teste de Tukey em nível de $5 \%$ de significância, utilizando-se o software Statistica, versão 9.0. Os dados apresentados nas tabelas representam os valores médios \pm o desvio padrão $(n=3)$.

\section{Resultados e discussão}

Os dados apresentados na Tabela 1 demonstram que o US afetou de forma significativa $(p<0,05)$ a concentração de PT do suco de uvas Isabel. Todos os tratamentos apresentaram elevação no teor de polifenóis das amostras, atingindo valores até $83 \%$ superiores em relação ao controle. Os resultados observados parecem estar na dependência da dose de US aplicada, sendo os maiores valores de PT encontrados em

Tabela 1. Valores médios de polifenóis totais (PT) do suco de uvas Isabel submetidas a diferentes doses de ultrassom (US).

\begin{tabular}{cccc} 
Tratamento & $\begin{array}{c}\text { Densidade de } \\
\text { potência de } \\
\text { US }\end{array}$ & $\begin{array}{c}\text { Tempo de } \\
\text { exposição } \\
\text { (minutos) }\end{array}$ & $\begin{array}{c}\text { PT } \\
\text { (mg. } \mathbf{L}^{-1} \text { EAG) }\end{array}$ \\
Controle & 0 & 0 & $549.8 \pm 19.0^{\mathrm{e}^{*}}$ \\
T1 & & 1 & $872.1 \pm 51.4^{\mathrm{abc}}$ \\
T2 & $53{\mathrm{~W} . \mathrm{cm}^{-2}}^{\mathrm{b}}$ & 5 & $721.7 \pm 16.3^{\mathrm{d}}$ \\
T3 & & 10 & $768.9 \pm 2.7^{\mathrm{cd}}$ \\
T4 & & 1 & $841.1 \pm 79.0^{\mathrm{bcd}}$ \\
T5 & $113{\mathrm{~W} . \mathrm{cm}^{-2}}$ & 5 & $1007.2 \pm 74.1^{\mathrm{a}}$ \\
T6 & & 10 & $984.5 \pm 51.6^{\mathrm{ab}}$ \\
\hline
\end{tabular}

*Médias seguidas pelas mesmas letras na vertical não diferem entre si pelo teste de Tukey a 5\% de significância. amostras sonicadas numa densidade de potência maior (113 W.cm-2), sobretudo com um tempo de aplicação de cinco minutos (T5).

Segundo trabalhos anteriores, o US também promoveu o aumento de compostos fenólicos em amendoins (RUDOLF e RESURRECCION, 2005) e café despolpado (NASCIMENTO et al., 2008), bem como de outros metabólitos secundários em cultura de células (WU e LIN, 2002). Nos estudos com amendoins, a densidade de potência e o tempo de aplicação de US, porém, não mostraram afetar de forma significativa os níveis de polifenóis, diferentemente dos resultados deste trabalho e dos encontrados por Wu e Lin (2002). Nesse estudo, o aumento na densidade de potência de 14 para $61 \mathrm{~mW} . \mathrm{cm}^{-3}$ também elevou a produção de compostos fenólicos em cultura de células de Panax ginseng tratadas com US. Os autores atribuíram o efeito a um aumento na atividade enzimática necessária para a biossíntese desses compostos.

O aumento no conteúdo de compostos fenólicos observado nos sucos de uvas Isabel pode ser resultado da indução do metabolismo de defesa celular da fruta em resposta ao uso do US. Conforme trabalhos anteriores, mesmo utilizando intensidades mais baixas, o US foi capaz de estimular a síntese de metabólitos secundários, como compostos fenólicos totais e resveratrol em amendoins (RUDOLF e RESURRECCION, 2005; SALES e RESURRECCION, 2010), e saponina (WU e LIN, 2002), shikonina (LIN e WU, 2002) e taxol (WANG et al., 2006; WU e GE, 2004), em cultura de células.

Embora não totalmente elucidados, os mecanismos específicos pelos quais o US exerce esse efeito parecem estar ligados à indução de respostas de defesa na planta, em decorrência do estresse mecânico causado pela propagação das ondas ultrassônicas. O processo de cavitação acústica, o qual envolve a formação de gases ou bolhas de vapor, causa um aumento na permeabilidade da membrana, uma desnaturação de DNA e proteínas e uma modificação na morfologia da célula (RUDOLF e RESURRECCION, 2007). Além disso, outros importantes eventos comumente observados no metabolismo de defesa vegetal e rotas de transdução de sinal já foram observados durante o tratamento com US, como o aumento do fluxo de íons através da membrana e a produção de espécies reativas de oxigênio, como o peróxido de hidrogênio (LIN e WU, 2002). A produção de peróxido de hidrogênio em plantas, conhecida como explosão oxidativa, ocorre como uma resposta de defesa ao ataque de patógenos e atua como um mensageiro secundário para sinalizar subsequentes reações de defesa em vegetais (ZHAO et al., 2005). Estes fatos reforçam a hipótese de que o US é capaz de estimular o metabolismo secundário de plantas levando a uma série de reações de defesa, que incluem o acúmulo de substâncias defensivas, como é o caso dos polifenóis.

$\mathrm{Na}$ avaliação sensorial de amostras controle e sonicadas (Tabela 2), o teste de ordenação de preferência 
Polifenóis totais e avaliação sensorial de suco de uvas Isabel tratadas com ultrassom

COMARELLA, C. G. et al.

Tabela 2. Módulo das diferenças entre os pares de somatório total do teste de ordenação de preferência em sucos de uvas Isabel tratadas ou não com ultrassom.

\begin{tabular}{lcccc}
\multicolumn{1}{c}{ Amostra } & Controle $\mathbf{( C )}$ & T3 & T5 & T6 \\
\hline Somatório total & $74^{\mathrm{b}}$ & $114^{\mathrm{a}}$ & $112^{\mathrm{a}}$ & $128^{\mathrm{a}}$ \\
Diferença $\times$ C & & $40^{*}$ & $38^{\star}$ & $54^{*}$ \\
Diferença $\times$ T3 & & & 2 & 14 \\
Diferença $\times$ T5 & & & 16 \\
$\quad$ Valor crítico tabelado $=31$ & & & \\
\hline
\end{tabular}

*significativo no nível de $5 \%$, se a diferença entre as somas das ordens de duas amostras diferirem por um valor maior ou igual ao valor crítico tabelado (Tabela de Newel-MacFarlane). amaior somatório corresponde à maior preferência.

demonstrou uma maior aprovação pelas amostras de suco de uvas submetidas ao US. O somatório obtido por estas amostras (T6, T3 e T5) foi significativamente superior ao alcançado pelo controle.

Além dos potenciais benefícios à saúde, a presença de compostos fenólicos no suco também influencia características sensoriais, como flavor e percepção do aroma retronasal do produto (TIWARI et al., 2010). As antocianinas, principais pigmentos presentes nas uvas, são as maiores responsáveis pela cor, enquanto que os taninos contribuem com a sensação de adstringência e amargor. Dessa forma, alterações nos níveis dessas substâncias podem influenciar sobremaneira as características de cor, odor e sabor, afetando a aceitação deste produto. Neste trabalho, o aumento no conteúdo de PT ocasionado pela exposição das uvas ao US influenciou de forma positiva as características sensoriais do suco, de modo que as amostras sonicadas foram as preferidas pelos julgadores.

\section{Conclusões}

A aplicação de diferentes doses de US em uvas Isabel levou a um aumento no teor de PT dos sucos em todos os tratamentos testados. O grau de resposta ao US é influenciado pela dose, sendo o tratamento com densidade de potência de $113 \mathrm{~W} \cdot \mathrm{cm}^{-2}$ e cinco minutos de exposição, o mais eficiente em promover a síntese de compostos fenólicos. A análise sensorial demonstrou que o US também contribuiu para a melhoria das características sensoriais dos sucos, sendo estes os preferidos pelos provadores. Assim, o US, como método físico, simples e quimicamente limpo, é uma tecnologia alternativa e promissora para a melhoria da qualidade geral de produtos como o suco.

\section{Agradecimentos}

À CAPES, pelo auxílio financeiro, e à Vinícola Velho Amâncio, pela doação das amostras.

\section{Referências}

INSTITUTO ADOLFO LUTZ - IAL. Análise Sensorial: Métodos Físico-químicos para Análise de Alimentos. 4. ed. São Paulo: IAL, 2008. 1020 p. Versão eletrônica.

INSTITUTO BRASILEIRO DO VINHO - IBRAVIN. Rio Grande do Sul Colhe Safra de Uva Recorde. Bento Gonçalves: IBRAVIN, 2011. Disponível em: <http://www.ibravin.org.br/ int_noticias. php?id=762\&tipo=N>. Acesso em: 18 jul. 2011.

KNORR, D.; ZENKER, M.; HEINZ, V.; LEE, D. U. Applications and potential of ultrasonics in food processing. Trends in Food Science \& Technology, Cambridge, v. 15, n. 5, p. 261-266, May 2004. http://dx.doi.org/10.1016/j.tifs.2003.12.001

LIN, L.; WU, J.; HO, K.-P.; QI, S. Ultrasound-induced physiological effects and secondary metabolite (saponin) production in Panax ginseng cell cultures. Ultrasound in Medicine and Biology, Oxford, v. 27, n. 8, p. 1147-1152, Aug. 2001. http://dx.doi. org/10.1016/S0301-5629(01)00412-4

LIN, L.; WU, J. Enhancement of shikonin production in singleand two-phase suspension cultures of Lithospermum erythrorhizon cells using low-energy ultrasound. Biotechnology and Bioengineering, New York, v. 78, n. 1, p. 81-88, Apr. 2002. PMid:11857284. http://dx.doi.org/10.1002/bit.10180

NASCIMENTO, L. C.; LIMA, L. C. O.; PICOLLI, R. H.; FIORINI, J. E.; DUARTE, S. M. S.; SILVA, J. M. S. F.; OLIVEIRA, N. M. S.; VEIGA, S. M. O. M. Ozônio e ultra-som: processos alternativos para o tratamento do café despolpado. Ciência e Tecnologia de Alimentos, Campinas, v. 28, n. 2, p. 282-294, 2008. http:// dx.doi.org/10.1590/S0101-20612008000200004

NETZEL, M.; NETZEL, G.; KAMMERER, D. R.; SCHIEBER, A.; CARLE, R.; SIMONS, L.; BITSCH, I.; BITSCH, R.; KONCZAK, I. Cancer cell antiproliferation activity and metabolism of black carrot anthocyanins. Innovative Food Science and Emerging Technologies, Amsterdam, v. 8, n. 3, p. 365-372, Sept. 2007. http://dx.doi.org/10.1016/j.ifset.2007.03.011

REZAEI, A.; GHANATI, F.; BEHMANESH, M.; MOKHTARI-DIZAJI, M. Ultrasound potentiated salicylic acid-induced physiological effects and production of taxol in hazelnut (Corylus avellana L.) cell culture. Ultrasound in Medicine and Biology, Oxford, v. 37, n. 11, p. 1938-1947, 2011. PMid:21835541. http://dx.doi. org/10.1016/j.ultrasmedbio.2011.06.013

RUDOLF, J. R.; RESURRECCION, A. V. A. Elicitation of resveratrol in peanut kernels by application of abiotic stresses. Journal of Agricultural and Food Chemistry, Washington, v. 53, n. 26, p. 10186-10192, Nov. 2005. PMid:16366713. http://dx.doi. org/10.1021/jf0506737

RUDOLF, J. L.; RESURRECCION, A. V. A. Optimization of transresveratrol concentration and sensory properties of peanut kernels by slicing and ultrasound treatment, using response surface methodology. Journal of Food Science, Chicago, v. 72 , n. 7 , p. $450-462,2007$ 
SALES, J. M.; RESURRECCION, A. V. A. Maximizing phenolics, antioxidants and sensory acceptance of UV and ultrasoundtreated peanuts. LWT - Food Science and Technology, Oxford, v. 43, n. 7, p. 1058-1066, Sept. 2010. http://dx.doi.org/10.1016/j. Iwt.2010.02.009

SINGLETON, V. L.; ROSSI, J. A. Colorimetry of phenolics with phosphomolybdic-phosphotungstic acid reagents. American Journal of Enology and Viticulture, Davis, v. 16, n. 3, p. 144-158, 1965.

TIWARI, B. K.; PATRAS, A.; BRUNTON, N.; CULLEN, P. J.; O'DONNELL, C. P. Effect of ultrasound processing on anthocyanins and color of red grape juice. Ultrasonics Sonochemistry, Amsterdam, v. 17, n. 3, p. 598-604, Mar. 2010. PMid:20015673. http://dx.doi.org/10.1016/j.ultsonch.2009.10.009

WANG, J. W.; ZHENG, L. P.; WU, J. Y.; TAN, R. X. Involvement of nitric oxide in oxidative burst, phenylalanine ammonialyase activation and taxol production induced by low-energy ultrasound in Taxus yunnanensis cell suspension cultures. Nitric Oxide, Orlando, v. 15, n. 4, p. 351-358, Dec. 2006. PMid:16753316. http://dx.doi.org/10.1016/j.niox.2006.04.261

WU, J.; GE, X. Oxidative burst, jasmonic acid biosynthesis, and taxol production induced by low-energy ultrasound in Taxus chinensis cell suspension cultures. Biotechnology and Bioengineering, New York, v. 85, n. 7, p. 714-721, Mar. 2004. PMid:14991649. http://dx.doi.org/10.1002/bit.10911

WU, J.; LIN, L. Elicitor-like effects of low-energy ultrasound on plant (Panax ginseng) cells: induction of plant defense responses and secondary metabolite production. Applied Microbiology and Biotechnology, Berlin, v. 59, n. 1, p. 51-57, 2002. http:// dx.doi.org/10.1007/s00253-002-0971-2

ZHAO, J.; DAVIS, L. C.; VERPOORTE, R. Elicitor signal transduction leading to production of plant secondary metabolites. Biotechnology Advances, Oxford, v. 23, n. 4, p. 283-333, June 2005. PMid:15848039. http://dx.doi. org/10.1016/j.biotechadv.2005.01.003 